\title{
Efeito do óleo de copaíba nos níveis séricos de uréia e creatinina em ratos submetidos à síndrome de isquemia e reperfusão renal ${ }^{1}$
}

\author{
Copaiba oil effect on urea and creatinine serum levels in rats submitted to kidney \\ ischemia and reperfusion syndrome
}

\author{
Marcus Vinicius Henriques Brito ${ }^{2}$, Raphael de Jesus Moreira ${ }^{3}$, Marcelo Luiz Couto Tavares ${ }^{3}$, Mariela Carolina Santos \\ Carballo $^{3}$, Thiago Xavier Carneiro ${ }^{3}$, Alex de Assis Santos dos Santos ${ }^{4}$ \\ 1. Trabalho realizado no Laboratório de Cirurgia Experimental (LCE) e Laboratório de Bioquímica do Centro de Ciências Biológicas e da \\ Saúde (CCBS) da Universidade do Estado do Pará (UEPA) em parceria com o Instituto Evandro Chagas (IEC). \\ 2. Professor Adjunto, Doutor; Coordenador da Disciplina Técnica Operatória, Cirurgia Experimental e Anestesiologia - UEPA; Coordenador \\ do Laboratório de Cirurgia Experimental da Universidade do Estado do Pará; Presidente da SOBRADPEC Regional do Pará. \\ 3. Graduandos do Curso de Medicina, Estagiários do Laboratório de Cirurgia Experimental - UEPA. \\ 4. Pós-graduando do curso de especialização em pesquisa aplicada às ciências da saúde - UEPA
}

\begin{abstract}
RESUMO
Objetivo: Avaliar o efeito do óleo de copaíba nos níveis séricos de uréia e creatinina em ratos submetidos a síndrome de isquemia e reperfusão renal. Métodos: Foram utilizados 18 ratos (Rattus norvegicus albinus),da linhagem Wistar, fêmeas, adultas, entre 90 e 120 dias de idade, pesando ente $200 \mathrm{~g}$ e 250g, distribuídos em dois grupos: Isquemia e Reperfusão (GIR), e Isquemia e Reperfusão Copaíba (GIRC). Os animais dos dois grupos foram submetidos à isquemia renal, de ambos os rins, por 50 minutos, seguida de reperfusão por 24, 48 e 72 horas, com posterior coleta de sangue e análise dos níveis séricos de uréia e creatinina. No GIRC, realizou-se, além da isquemia e reperfusão, a administração diária do óleo de copaíba na dose de $0,63 \mathrm{ml} / \mathrm{kg}$, por gavagem, sete dias antes do procedimento de isquemia renal. Resultados: Foi observada uma diminuição estatisticamente significante dos níveis séricos de uréia no GIRC em 24 e 48 horas de reperfusão renal e uma diminuição do nível sérico de creatinina no GIRC em 48 horas de reperfusão renal quando comparados com o grupo Controle.Conclusão: Segundo os procedimentos aplicados, o óleo de copaíba diminuiu os níveis séricos de uréia em 24 horas e 48 horas e os de creatinina nas 48 horas após o procedimento de isquemia e reperfusão renal em ratos.
\end{abstract}

Descritores: Copaíba. Síndrome de isquemia reperfusão. Uréia. Creatinina. Ratos.

\begin{abstract}
Purpose: To evaluate the copaiba oil effect on urea and creatinine levels in rats submitted to kidney ischemia and reperfusion syndrome. Methods: Eighteen Wistar rats (Rattus norvegicus albinus), aged between 90 and 120 days, weight between $200 \mathrm{~g}$ and $250 \mathrm{~g}$, were allocated in 2 groups $(\mathrm{n}=9)$ and submitted to 50 minutes of renal ischemia and reperfusion and treated or not with copaiba oil $(0,63 \mathrm{ml} / \mathrm{kg}$ daily seven days before ischemia). The nitrogen excrements were assessed at 24, 48 and 72 hours after ischemia period. Results: The urea serum level was smaller (p d” 0,05) at 24 and 48 hours, and the creatinine serum level was smaller at 48 hours in animals treated with copaiba oil (GIRC) than the GIR. Conclusion: The copaiba oil decreased significantly the urea serum level at 24 and 48 hours and the creatinine level at 48 hours after kidney ischemia and reperfusion in rats.
\end{abstract}

Key words: Copaiba. Ischemia and reperfusion syndrome. Urea. Creatinine. Rats.

\section{Introdução}

A síndrome de isquemia e reperfusão tem sido amplamente reconhecida como uma fonte importante de danos e conseqüências deletérias para órgãos, 1, 2, 3, 4, 5, 6 sendo descrita na literatura em várias condições clínicas tais como o infarto do miocárdio, isquemia cerebral e isquemia renal. ${ }^{2,3}$

No rim, a lesão induzida por isquemia e reperfusão é o principal fator etiológico da insuficiência renal aguda (IRA), que se caracteriza, entre outros achados, por uma elevação transitória nas taxas séricas de creatinina. ${ }^{2,3,4}$ A geração de injúria renal após isquemia e reperfusão, por sua vez, envolve três principais rotas metabólicas: via da xantinaoxidase, via do óxido nítrico e a via do ácido araquidônico. $1,2,3,4,5,6$

Desta forma, várias substâncias como as vitaminas C, D e E, e drogas como verapamil, alopurinol e octreótida, têm sido utilizadas em estudos experimentais com o objetivo de minimizar alterações deletérias causadas na função renal decorrente de tal circunstância de injúria. 2, 3, 4,7

Fuentes e col. ${ }^{7}$ sugeriram o efeito protetor da octreótida 
em relação aos danos causados pela isquemia e reperfusão renal em ratos ao observarem a ocorrência de diminuição dos níveis séricos de creatinina no grupo estudo. Rhoden e col. ${ }^{3}$, ao estudarem os efeitos do alopurinol na função renal de ratos após isquemia e reperfusão, detectaram também, nos animais que receberam tal droga, uma diminuição na concentração sérica de creatinina, a qual se manteve até 96 horas após o procedimento cirúrgico.

Brito e col. ${ }^{8}$ estudaram o efeito do óleo de copaíba na função renal de ratos administrando o óleo por gavagem nas doses de $0,06 \mathrm{ml} / \mathrm{kg}$ e $0,63 \mathrm{ml} / \mathrm{kg}$ durante 14 dias e concluíram que este óleo não alterou, segundo o método adotado, a função renal. Quanto ao óleo de copaíba, este consiste no produto da exsudação patológica do lenho de árvores do gênero Copaifera, típica da América tropical e comumente encontrada na Amazônia. Este óleo, um dos mais conhecidos produtos fitoterápicos amazônicos, é reconhecido pela sua grande utilização na medicina popular. Isto se deve as suas propriedades antiinflamatória e cicatrizante de feridas, principalmente sobre as vias pulmonares e renais, além de ser considerada pela população como desinfetante de secreções. ${ }^{8,9,10,11,12}$

Desta forma, levando em consideração a vasta utilização pela população e a necessidade de trabalhos que esclareçam melhor os efeitos deste fitoterápico, o presente estudo tem como objetivo avaliar o efeito do óleo de copaíba nos níveis séricos de uréia e creatinina em ratos submetidos à isquemia e reperfusão renal.

\section{Métodos}

O óleo de copaíba, extraído da espécie Copaifera multijuga Hayne, foi proveniente do município de Cametá, Estado do Pará, Brasil, na forma de óleo bruto e submetido à análise físico-químico pelo Departamento de Engenharia Química da Divisão de Engenharia de Processos de Produtos Naturais da Universidade do Estado do Pará. Neste estudo foram utilizados 18 ratos (Rattus norvegicus albinus) da linhagem Wistar, fêmeas, adultas, entre 90 e 120 dias de idade, pesando entre 200 e $250 \mathrm{~g}$, provenientes do Biotério do Instituto Evandro Chagas (Belém - Pará), previamente adaptados ao Laboratório de Cirurgia Experimental da Universidade do Estado do Pará, por um período de 15 dias antes do início do experimento, mantidos em ambiente controlado.

Água e ração foram oferecidos ad libitum durante todo o período de realização do experimento, segundo normas do COBEA. Os animais foram distribuídos em 2 grupos de 9 ratos cada:

Grupo Isquemia e Reperfusão (GIR): todos os animais foram submetidos à isquemia renal bilateral por 50 minutos seguida de reperfusão. Posteriormente, foram colhidas amostras de sangue $(3,0 \mathrm{ml})$ em períodos de 24,48 e 72 horas após o procedimento cirúrgico para determinação dos níveis séricos de uréia e creatinina.

Grupo Isquemia e Reperfusão - Copaíba (GIRC): administrou-se óleo de copaíba, por gavagem, na dose de $0.63 \mathrm{ml} / \mathrm{kg}$ durante sete dias prévios ao procedimento cirúrgico nos animais deste grupo. Todos os animais foram então submetidos à isquemia renal bilateral por 50 minutos seguida de reperfusão. Posteriormente, foram colhidas amostras de sangue (3,0 ml) em períodos de 24, 48 e 72 horas após procedimento cirúrgico para determinação dos níveis séricos de uréia e creatinina. Os valores de referência de uréia e creatinina utilizados foram os mesmos determinados por Waynforth e Flecknell (1992), sendo o nível sérico de uréia 41,56 mg/dl e de $0,48 \mathrm{mg} / \mathrm{dl}$ para creatinina. ${ }^{8}$

Para realização dos procedimentos operatórios os animais foram anestesiados com éter etílico, via inalatória. ${ }^{13}$ Após o estabelecimento do plano anestésico, foram posicionados em decúbito dorsal e submetidos à tricotomia e anti-sepsia com álcool iodado na região abdominal. Foi realizada laparotomia mediana superior de $3 \mathrm{~cm}$ de extensão. As alças intestinais afastadas e mantidas umedecidas com gaze embebida em soro fisiológico. Os rins foram dissecados da gordura perirrenal e seus pólos superiores liberados das supra-renais. Os pedículos renais foram cuidadosamente dissecados com o auxílio de microscópio cirúrgico DF Vasconcellos 9000, identificando-se artéria, veia, e ureter proximal. As artérias renais foram identificadas e isoladas, permitindo o pinçamento destas com pinças vasculares atraumáticas (EDLO 7-794) durante 50 minutos. Posteriormente, as pinças foram retiradas e o fluxo sanguíneo foi restabelecido. Seguiu-se revisão da cavidade e fechamento da parede abdominal, por planos, com fio seda 2.0. Vinte e quatro horas após isquemia e reperfusão, três animais de cada grupo foram novamente anestesiados e submetidos a laparotomia xifopúbica com visibilização da veia cava abdominal, punção e retirada de $3 \mathrm{ml}$ de sangue, o qual foi imediatamente enviado ao Laboratório de Bioquímica da Universidade doEstado do Pará para análise dos níveis séricos de uréia e creatinina. Por fim, os animais foram submetidos à eutanásia por inalação de altas doses de éter etílico em ambiente saturado.

Com 48 e 72 horas, outros três animais de cada grupo foram submetidos aos mesmos procedimentos descritos a fim de serem coletadas novas amostras de sangue. Os resultados obtidos foram posteriormente submetidos à análise estatística pelo método Teste U de Mann-Whitney, considerando o índice de significância á= 0,05 ou 5\%.

\section{Resultados}

TABELA 1 - Níveis séricos de uréia (mg/dL) nos Grupos Isquemia e Reperfusão (GIR) e Isquemia e Reperfusão - Copaíba (GIRC) em 24, 48 e 72 horas de isquemia reperfusão renal em ratos.

\begin{tabular}{ccccccc}
\hline \multicolumn{2}{c}{$2 \mathbf{2 4}$ horas } & \multicolumn{2}{c}{$\mathbf{4 8}$ horas } & \multicolumn{2}{c}{$\mathbf{7 2}$ horas } & \\
GIR & GIRC* & GIR & GIRC* & GIR & GIRC & Referência \\
\hline 115 & 105 & 107 & 72 & 70 & 67 & 41.56 \\
144 & 98 & 95 & 50 & 72 & 70 & \\
140 & 82 & 88 & 70 & 65 & 64 & \\
\hline
\end{tabular}

*p $\leq$ 0,05 (Teste U de Mann-Whitney) 
TABELA 2 - Níveis séricos de creatinina (mg/dL) nos Grupos Isquemia e Reperfusão (GIR) e Isquemia e Reperfusão - Copaíba (GIRC) em 24, 48 e 72 horas de isquemia reperfusão renal em ratos.

\begin{tabular}{ccccccc}
\hline \multicolumn{2}{c}{24 horas } & \multicolumn{2}{c}{$\mathbf{4 8}$ horas } & \multicolumn{2}{c}{$\mathbf{7 2}$ horas } \\
GIR & GIRC & GIR & GIRC* & GIR & GIRC & Referência \\
\hline 0,3 & 0,4 & 0,8 & 0,4 & 0,4 & 0,4 & 0.48 \\
0,5 & 0,4 & 0,6 & 0,2 & 0,4 & 0,4 & \\
0,4 & 0,3 & 0,6 & 0,3 & 0,4 & 0,3 & \\
\hline
\end{tabular}

*p $\leq$ 0,05 (Teste U de Mann-Whitney)

\section{Discussão}

O processo de isquemia e reperfusão determina lesão celular através de vários mecanismos, que envolvem a quase totalidade dos componentes do metabolismo celular. 1, 2,3,4, 5,6,7 Estas alterações ocorrem tanto em situações fisiológicas (envelhecimento) como patológicas (isquemia cerebral e renal, necrose hepática). Sabe-se que o dano celular na síndrome isquêmico-reperfusional é decorrente de alterações da estrutura das membranas lipídicas da célula e de suas organelas, que são conseqüência de processos iniciados já na fase de isquemia, porém intensificados durante a reperfusão tecidual. 1, 2, 3, 4, 5, 6, 7

Dentre os mecanismos envolvidos na fisiopatologia dos danos causados pela isquemia e reperfusão estão as vias metabólicas da xantina-oxidase, óxido nítrico e ácido araquidônico. 1, 2, 3, 4, 5, 6, 7

No presente estudo, a repercussão destes danos foi avaliada pela verificação da função renal por meio da determinação dos níveis séricos de uréia e creatinina de animais submetidos à isquemia renal transitória seguida de reperfusão, com ou sem administração prévia de óleo de Copaíba. Os níveis séricos de creatinina e a concentração sanguínea da uréia são dois importantes fatores para se avaliar o Índice de Filtração Glomerular (IFG), níveis estes que podem estar elevados ou diminuídos em determinadas situações. ${ }^{14,15}$

A uréia do organismo é proveniente da ingesta alimentar na sua maioria, sendo formada no fígado e excretada pelo rim. Após a lesão renal causada pela síndrome de isquemia e reperfusão, percebe-se que os níveis séricos de uréia aumentaram tanto no GIR quanto no GIRC (Tabela 1), mas esse aumento foi menor e estatisticamente significante no GIRC no período de reperfusão de 24 horas e 48 horas.

A elevação dos níveis séricos da uréia em ambos os grupos pode ser explicada ou pela lesão tecidual renal causada pela isquemia de 50 minutos realizada em ambos os rins seguida de reperfusão destes órgãos, causando mais lesões neste parênquima renal, diminuindo assim a capacidade dos rins de filtração da uréia que se acumulou no sangue, ou por uma não alteração da função renal, levando a reabsorção ávida de sódio e água filtrados, elevando a concentração de uréia no líquido tubular e elevando, assim, a reabsorção da uréia.Essas respostas diminuem a depuração da uréia. ${ }^{14,15}$.

Os menores níveis de uréia no GIRC em 24h e 48h podem ter sido ocasionados pela diminuição da permeabilidade vascular a agentes pró-inflamatórios causada pelo óleo de copaíba, ${ }^{12}$ que diminuiu a migração de agentes tóxicos para o parênquima renal amenizando assim a lesão deste órgão. Nos grupos de reperfusão de $72 \mathrm{~h}$ os níveis de uréia foram estatisticamente semelhantes, porém menores que nos grupos $24 \mathrm{~h}$ e $48 \mathrm{~h}$ devido a um progressivo restabelecimento da função renal após a síndrome de isquemia e reperfusão. A creatinina é um composto endógeno obtido por meio do metabolismo muscular da creatina, sendo constante a sua produção pelo organismo. ${ }^{14,15}$

A maioria da creatina produzida pelo organismo é filtrada pelos rins e excretada por eles, tornando-se assim um indicador mais fiel da função renal. ${ }^{14,15}$

Nos resultados da pesquisa percebe-se que os níveis de creatinina estão, em todos os grupos da pesquisa (menos no grupo controle em $48 \mathrm{~h}$ de reperfusão), menores que os valores de referência adotados pelos autores, ${ }^{8}$ estando o GIRC com os valores menores ainda (Tabelas 2). Isto pode ser explicado de duas formas: ou os valores de referência não se aplicam devido à diferença das amostras estudadas (idade, peso, espécie, ambiente), ou por uma compensação da função renal em excretar a creatinina retida durante a síndrome isquêmica.

Contudo, observou-se no GIR um pico de aumento desta excreta em 48 horas após o procedimento cirúrgico, seguido de posterior decréscimo após 72 horas. Já no GIRC, não houve este pico de aumento em nenhum dos períodos de coleta, inclusive, com 48 horas após a isquemia e reperfusão, os níveis séricos de creatinina já se apresentavam estatisticamente iguais aos valores de normalidade (Tabela 2).

Tais achados demonstraram que a administração prévia, por sete dias, à isquemia e reperfusão, do óleo de copaíba por gavagem, protegeu a função renal dos animais nas 48 horas após a isquemia e reperfusão.

\section{Conclusão}

Segundo os procedimentos aplicados, o óleo de copaíba diminuiu os níveis séricos de uréia em 24 horas e 48 horas e os de creatinina nas 48 horas após o procedimento de isquemia e reperfusão renal em ratos.

\section{Referências}

1. Silva JR OC, Centurion S, Pacheco EG, Brisotti JL, Oliveira AF, Dal Sasso K. Aspectos básicos da lesão de isquemia e reperfusão e do pré-condicionamento isquêmico. Acta Cir Bras. 2002; 17(3). Disponível em URL: http:// www.scielo.br/acb.

2. Rhoden EL, Mauri M, Petteffinns L, Dacanal F, Pilla M, BellóKlein A, Teloken C, Barros E, Rhoden CR. Efeitos do alopurinol sobre a lipoperoxidação de membranas celulares renais na síndrome da isquemia e reperfusão: Estudo experimental em ratos. Acta Cir Bras. 1998;13: 73-9.

3. Rhoden EL, Mauri M, Dacanal F. Efeitos do alopurinol na função renal após isquemia e reperfusão do rim: Estudo experimental em ratos. Rev Bras Cir. 1997; 87:225 - 8.

4. Leal DM, Júnior ST, Suaid HJ, Cologna AJ, Martins ACP, Roselino JES. Proteção funcional do rim com lovastatina após isquemia e reperfusão renal. Acta Cir Bras. 2001; 
16(1). Disponível em URL: http://www.scielo.br/acb.

5. Miranda LEC, Viaro F, Ceneviva R, Evora PRB. As bases experimentais da lesão por isquemia e reperfusão do fígado. Revisão. Acta Cir Bras. 2004; 19(1). Disponível em URL: http://www.scielo.br/acb.

6. Willet K, Macedo DV, Detrys O. Evens A. Mitochondrial oxidative phosphorilation injuries occurring in sito and in vivo. Transplant Proc. 1995; 27:2827-8.

7. Fuentes FR, Basterra JV, Hernandez EG. Previene la octreótida el dano renal por isquemia e reperfusion? Bol Col Mex Urol. 1995;12:41-5.

8. Brito MVH, Tavares MLB, Moura LGS, Lima JT. Efeito do óleo de copaíba na função renal de ratos. Rev Para Med. 2001; 15: 28-32.

9. Junior OGS, Damous SHB, Lamarão LG. Revisão critica do uso médico do óleo de copaíba. Rev Para Med. 2000;14:71-4.

10. Estrela E. Plantas medicinales Amazônicas: Realidad y Perspectivas. Peru: EPU: 1995. p.223-4.
11. Fernandes RM, Pereira NA, Paulo LG. Antinflamatory activity of copaíba balsam. Rev Bras Farm. 1992; 73:53-6.

12. Basile AC, Sertié JA, Freitas PC, Zanine AC. Antiinflamatory activity of oleoresin from Brazilian Copaifera. J Ethnopharmacol. 1988; 22:101-9.

13. Brito MVH, Brito NMB, Almeida AJB, Santos MRLC. Vaporizador artesanal de éter para cirurgia experimental em pequenos roedores. Acta Cir Bras. 1998, 13: 3-7.

14. Guyton AC. Tratado de fisiologia médica. $9^{\mathrm{a}} \mathrm{ed}$. Rio de Janeiro (RJ): Guanabara Koogan; 1997.

15. Mitch WE. Insufuciência renal aguda. In: Gildman L, Bennett JC. Cecil: Tratado de Medicina Interna. 21 ed. Rio de Janeiro (RJ): Guanabara Koogan; 2001.

16. Cotran RS, Kumar V, Collins T. Robbins: Patologia estrutural e funcional. 6 ed. Rio de Janeiro (RJ): Guanabara Koogan; 2000.

17. Góes GM. Cirurgia urológica. In: Goffi FS. Técnica cirúrgica: Bases anatômicas, fisiopatológicas e técnicas da cirurgia. 4 ed. São Paulo (SP): Atheneu; 1997.

\section{Correspondência}

Marcus Vinícius Henriques Brito

Travessa Apinages, 630/201

66033-170 Belém-PA

mnbrito@amazon.com.br
Conflito de interesse: nenhum Fonte de financiamento: nenhuma

Recebimento: 12/01/2005

Revisão: 10/02/2005

Aprovação: 17/03/2005

\section{Como citar este artigo:}

Brito MVH, Moreira RJ, Tavares MLC. Efeito do óleo de copaíba nos níveis séricos de uréia e creatinina em ratos submetidos à síndrome de isquemia e reperfusão renal. Acta Cir Bras. [periódico na Internet] 2005 Maio-Jun;20(3). Disponível em URL: http://www.scielo.br/acb 